\title{
A PERICIA MÉDICA NOS CASOS DE SIMULAÇÃO EM INFORTUNÍSTICA
}

\author{
TESE APRESENTADA AO \\ PRIMEIRO CONGRESSO BRASILEIRO DE DIREITO SOCIAL \\ em 13-V-1941, sustentada perante a D. Subcomissão de Acidentes \\ do Trábalho e debatida em 17-V-1941 \\ DR. ANTÔNIO MIGUEL LEÃO BRUNO \\ Doutor em Medicina. Bacharel em Ciências Jurídicas e Sociaís. \\ Assistente Adjunto da Cadeira de Medicina Legal da Faculdade \\ de Medicina da Universidade de São Paulo. Chefe da Secção de \\ Psícologia Experimental- do Instituto Oscar Freire (Departamento \\ de Medicina Legal da Faculdade de Medicina da Universídade \\ de S. Paulo). Médico Legista do Estado.
}

\section{1. ${ }^{\mathrm{a}}$ PARTE}

\section{A CLASSIFICAÇÃO DAS MODALIDADES DE SIMULAÇÃO}

I

\section{A SIMULAÇÃO EM INFORTUNISTICA - SUA DEFINIÇÃO}

Em trabalho relatado na Segunda Semana Paulista de Medicina Legal, em 7 de novembro de 1940, definimos a simulação em infortuñistica como sendo - o conjunto de manifestações concientes e artificiais por via das quais se concretiza a vontade do empregado para iludir terceiros (o médico, o empregador, as companhias de seguros, advogados, juizes, curadores especiais das vítimas de acidentes do trabalho, etc.), tendo em vista obter determinadas vantagens.

\section{II}

\section{MODALIDADES DE SIMULAÇ̃̃O}

Para se compreender bem o aspecto médico-legal do problema, vejamos as diferentes modalidades de simulação.

Aproveitando-nos das diferentes classificações já existentes, vámos - de acordo com a nossa experiência e com a gravidade dos méros de que lança mão o simulador - considerar na seguinte ordem âs modalidades de simulação: 
$\left.1 .^{\circ}\right)$ Simulação verdadeira;

$\left.2 .^{\circ}\right)$ Agravação voluntária;

3. $\left.{ }^{\circ}\right)$ Imputação inexatá ;

4. $\left.{ }^{\circ}\right)$ Dissimulação;

5. ${ }^{\circ}$ Exageração.

1. $\left.{ }^{\circ}\right)$ Simulação verdadeira $-E^{\prime}$ aquela modalidade de simulação por via da qual o seu autor inventa ou imita uma lesão corporal, perturbação funcional ou doença, afim de, com este meio ilícito, auferir vantagens pessoais. (A. M. LEÃo. BRUNo).

$\mathrm{Na}$ simulação verdadeira há a simulação do acidente, vale dizer, a simulação da causa (por isso que, na verdade, não se registou nenhuma lesão corporal, perturbação funcional, ou doença, produzida pelo exercício do trabalho ou em consequência dele) e a simulaçấo dos pretendidos efeitos desse pseudo-acidente.

Nesta modalidade podem ser incluidas as simulações de fenômènos assim subjetivos como objetivos, maxime daqueles.

Dentre os primeiros mencionem-se: A dor, anestesias, nevroses, epilepsia, paralisias, cegueira, surdez, mutismo, etc.

E dentre os segundos: Afecções cutâneas, hemoptises, hematemeses, albuminúrias, henatúrias, etc.

2. ${ }^{\circ}$ Agravação voluntária - Agravação é o ato de agravar. No capítulo da simulação em infortunística, entende-se por agravação (agravação conciente, naturalmente, visto que é a única a merecer reparos nesta exposição) - o ato por via do qual o empregado recorre, voluntariamente, a meios ilícitos para fazer peorar o estado da sua lesão corporal, perturbação funcional ou doença, com o fito de auferir determinadas vantagens (Definição proposta pelo A. na Segunda Semana Paulista de Medicina Legal).

Intencionalmente uma lesão pode ser entretida ou agravada. Sirvam de exemplo:

a) A aplicação de substâncias irritantes ñum ferimento;

b) A inobservância das prescrições médicas (como, à guisa de exemplo, a locomoção antes do prazo médio da consolidação óssea e a retirada do penso: antes da indicação).

3..$^{\circ}$ Imputação inexata - $E^{\prime}$ aquela modalidade de simulação por via da qual o empregado atribue dolosamente (IMPUTĀÇÃO INEXATA CONCIENTE) ou, até, de boa fé (IMPUTAÇÃO INEXATA INCONCIENTE), a um traumatismo de fato ocorrido, uma lesão corporal, perturbação funcional ou doença preexistente ou superveniente mesmo, mas sem que haja nexo real de causa e efeito (A. M. Leão Bruno). Passivel de penalidade, naturalmente, somente quando a imputação inexata for dolosa (IMPUTAÇÃO INEXATA CONCIENTE). Para esta última modalidade, de simulação reservamos o nome de IMPUTAÇÃO FALSA. 


\section{$4^{\circ}{ }^{\circ}$ Dissimulação - Dissimulação em infortunística é} aquela espécie de fingimento que consiste em ocultar o seu autor uma determinada lesão corporal, perturbação funcional ou doença, com o fito de ser tido como são, afim de obter um emprego ou um seguro de vida oú, ainda, para, após ter ingressado no trabalho com esse ardil, atribuir uma origem traumáticà ao mal de que já padecia e, destarte, exigir ilicitamente uma indenização (A. M. Leão Bruno).

Na SIMULAÇÃO VERIDADEIRA, já vimos, o seu autor inventa ou imita uma lesão corporal, perturbação funcional ou doença. Na DISSIMULAÇÃO - não há invenção ou imitação duma lesão corporal, perturbação funcional ou doença. Há realmente uma lesão corporal, perturbação funcional ou doença. Mas, neste último caso, o mal de que se lamenta o empregado já preexistia. Já preexistia e, de caso pensado, fora cuidadosamente encoberto.

\section{Ouçamos a Francesco Carrara:}

"Ao-passo-que na simulação se faz aparecer o que não existe, na dissimulação se esconde aquilo que existe. Uma, provoca a falsa crença dum estado não real; a outra, oculta o conhecimento dum estado existente. Aquela, tem em mira uma ilusão externa; esta, uma ocultação interna. Dissimula-se, destarte, a ira, o ódio, o rancor. A finalidade do procedimento do indivíduo, assim na simulação como na dissimulação, é - enganar, carater fundamental das várias formas simulatórias. $\mathrm{Na}$ simmlação se quer enganar porisso que o seu àutor pretende que se acredite na existência dum estado mendaz e, na dissimulação, na inexistência dum estado efetivo. A simulação é um fantasma; a dissimulação, uma mascara"

De regra, mui dificil é, em infortunística, fazer um diagnóstico "a posteriori", da dissimulação. De feito, após o contrato de locação de trabalho é já se encontrando o empregado em pleno exercício de suas atividades - estas podem, muitas vezes, mascarar a fraude.

Por isso registe-se, desde agora, a importância capital do exame meticuloso do empregado antes de ser efetuado o contrato de locação de serviço.

5..$^{\circ}$ Exageração - Para Antônio de Morais Silva, cxa geração é "ato de exagerar, encarecimento, amplificação"; e. e.ragerar significa - "amplificar, encarecer, representar as cousas maiores do que são; exagerar as suas grandezas, a sua dor, seus males"

Segundo José Maria de Almeida e Araujo Corrêa de LacerDA, exagérar, deriva do lat. "exaggero, as; de "ex", e "aggero, as", por em montão, amontoar : "ad", e "gero, is", trazer; levar; negociar ; administrar; fazer, etc." Quer dizer "encarecer, representar uma coisa, um fato maior do que é na realidade, amplificar, engrandecer...": "Quasi. sempre exageramos o perigo, os bens e males. Tressan". Sinonímia comparativa: Exagerar, encarecer "Exagerar recai mais propriamente sobre as circunstâncias que fazem nota- 
vel a coisa exagerada, 'e encarecer sobre as que a fazem apreciayel, conservando o verbo neste sentido figurado (em que é, sinônimo de exagerar) a propriedade do seu sentido reto"... "Um casamenteiro exagera as riquezas, e encarece as boas prendas da dama que propõe"...

Nos infortúnios do trabalho -o autor da interessante modalidade de simulação que ora abordamó - exagera a lesão corporal, perturbação funcional ou doença e, ao mesmo tempo, encarece-a, isto é, pretende fazer subir o preço da indenização...

Em infortunística, pois dizemos que há exageração conciente (a única que nos interessa neste estudo) - quando o emprégado anplifica fingidamente o seu mal com o intuito de iludir terceiros e tendo em vista obter o máximo provento de um acidente, inda que insignificante (A. M. LEÃo BrUNo)

\section{2. ${ }^{\mathrm{a}}$ PARTE}

\section{A PERfCIA MÉdICA NOS CASOS DE SIMULAÇÃO EM INFORTUNISTICA}

\section{A SINTOMATOLOGIA DAS DOENÇAS E A INFLUENCIA ETIOLOGICA DOS TRAUMATISMOS}

Já em 1594 dizia J. B. Silvaticus:

"Morborum omnium et præsertim internorum signa certa pathegnomonica ante omnia probe sciri necesse est".

De feito, a primeira condição requerida para a descoberta da fraude nos casos em apreço - é o conhecimento perfeito da sintomatologia da doença de que se queixa o empregado.

Não apenas, contudo, o perito deve possuir 'o conhecimento exato da sintomatologia das diferentes doenças cuja existência é precișo confirmar ou infirmar. Para justificar as causas que as motivaram, deve, ele, ainda, possuir uma noção tão perfeita quão possivel da influência etiológica dos traumatismos.

Quando um acidente cria por sua ação direta sobre o organismo do empregado, quer uma mutilação, quer uma perturbação que nossos meios de investigação tornam evidentes - não podemos duvidar da relação de causa e efeito.

Todaviá, se algum tempo após um infortúnio do trabalho - em que se não registaram assim lesões abertas como perturbações funcionais sérias - surde uma afecção médica, infecciosa ou não, o nexo causal perde sua evidência, e a perícia médica, em tais condições, oferece dificuldades reais. O médico, pois, deve estar habilitado para 
indicar com exatidão a influência que pode exercer um traumatismo sòbre a eclosão, às vezes tardia, duma doença; sobre a evolução duma afecção preexistente ou latente; ou, inversamente, a ação do estado de saude anterior sobre as sequências imediatas e remotas dum traumatismo.

Thornot aprecia- da maneira seguinte a influência etiológica dos traumatismos :

I - O traumatismo cria lesões locais elementares cuja evolução determina afecções locais ou pode tornar-se o ponto de partida duma afecção geral;

II - $O$ traumatismo detemina uma modificação geral do drganismo que foi atingido, modificação que se traduz pelo desenvolvimento duma afecção geral.

Necessário é que o médico legista baseie seu diagnóstico, de simulação em elementos objetivos de valor.

Não é a simples suspeita, nem a grande práticá do perito em matéria de acidentes do trabalho, o que autoriza a diagnosticar uma simulação.

"Quando estiverdes em presença dum caso dificil, embaraçoso, eu vos convido com empenho a não pensar desde logo na simulação; "se é verdade que não vos deveis esquecer nunca da possibilidade da fraude, nesses casos, não menos verdade é que só vos haveis de deter nessa idéia quando forem verificados sintomas realmente suspeitos" Tal o conselho de Boisseau.

Somente, pois, após ụma certeza absoluta é que deve ser feito um juizo a respeito.

No exame dos indivíduos atingidos de doenças internas provocadas ou simuladas, são merecedoras de reparo as șeguintes mónitas de Heller:

I - Verificar se há falta de concordância entrè os sintomas mórbidos acusados pelo indivíduo e os sintomas comuns da doença simulada;

II - Verificar se se processa uma evolução irregular do quadro clínico, quando a ação do agente provocador se esbate e que, a este, um novo apelo por parte do simulador se faz mistér;

III - Fazer um exame completo do corpo do indivíduo, em momentos inesperados para este;

IV - Pesquizar se houve ou não absorção de substâncias prejudiciaị, ou, pelo contrário, se houve ou não a ingestão de substâncias indispensaveis ao perfeito metabolismo: se o emágrecimento, por exemplo, nã̀o é obra duma alimentação voluntariamente insuficiente.

Há inverossimilhança em a narrativa das causas ou nas circunstâncias do acidente? 
- Apresenta a sintomatologia particularidades inexplicaveis?

- A duração, a marcha da afecção - são anormais?

Nessas hipóteses, é preciso pensar na simulação - diz Remy.

A maneira mais segura para desmascarar uma simulação é ó exame minucioso, repetido - utilizando-nos de todos os recursos da técnica moderna para o exame quer clínico quer de laboratório.

E' bem de ver, como ensina LÉon GALLEz; que, se a-pesar-do emprego de todos os métodos modernos de investigação, nã̃o chegamos a objetivar a mínima alteração de saude, torna-se evidente que os sintomas subjetivos de que se queixa o empregado - são mais do que suspeitos. De mais a mais, eis dous pontos de reparo preciosos que o perito deverá pesquisar com cuidado e cuja verificação permitirá diagnosticar uma simulação:

1. $\left.{ }^{\circ}\right)$ Falta de concordância entre a maneira dé ser, a conduta', o comportamento geral do indivíduo e a doença alegada;

$2^{\circ}$ ) Contradição no quadro clíníco que ele simula: associaçãá de sintomas que, se realmente coexistissem, colocaria o caso em desa- cordo com todas as leis da Patologia.

A atenção do médico legista não se deve fixar tão somente no. estado de saude atual do ferido ou do doente ou do pseudo-acidentado. Deverá estar tambem voltada para o estado de saude anterior, para os antecedentes pessoais ou hereditários e, ainda, para a constituição individual do examinando.

Muita vez - são esses elementos que explicam determinados estados patológicos e determinadas complicações, os quais o intereșsado, sem embargo, imputa unicamente ảo traumatismo.

De feito, todos os cuidados acima são indispensaveis, porisso que, como ensina ChAvigny e repetem todos os autores, "a simulação não se adivinha: ela se diagnostica e o seu diagnóstico, frequentemente; se encontra exposto a erros inevitaveis".

\section{TRAUMATISMOS E PERTURBACÓES ANTERIORES DA SAUDE}

VERNEUIL demonstrou, dum modo preciso, a série de modificações que os estados diatésicos ou constitucionais podem exercitar sobre os traumatismos.

TERRIER, por seu lado, mostrou que os ferimentos podem sofrer a influência dos seguintes estados patológicos:

I - Afecções diatésicas: artritismo, tuberculose, esçrofulose, herpetismo, diáteșe neoplásica;

II - Intoxicações: sífilis, alcoolismo, paludismo, saturnismo, hidrargirismo, etc.;

III - Doenças crônticas oưagudas. 
Traumatismos e doenças constitucionais podem, por sem dúvida, exercer influências récíprocas. Eis as modalidades que se podem apresentar:

I - O traumatismo e a doença constitucional evolvem paralelamente sem que um influencie o outro (Ĺón GALLEZ);

II - A doença constitucional complica a evolução do traumatismo (LÉON GALLEZ);

III - $O$ traumatismo estimula, aviva, acelera, ou agrava a doença constitucional (Forgue).

Mui delicada é a ação do perito na importante questão da preexistência mórbida que vem agravar a lesão adquirida no exercício do trabalho.

Convem aquí atendida a lição do Mestre:

"Muitas das dúvidas que a questão do estado anterior suscita na prática, poderiam ser em boá parte desviadas, exigindo-se, nas indústrias, exame prévio do candidato por meio do qual se estabelecesse, com o maior rigor possivel, a capacidade de trabalho e o estado de saude individual. Já se caminha para isso. Até lá, em casa cașo concreto, os peritos, de acordo com os aplicadores da Lei, devem en-carrègar-se de minorar as dificuldades práticas; considerando que não há identidade absoluta de organísmo humano, mas que cada indivíduo apresenta as suas taras, as sulas miopragias especiais e particulares, como bem sabem, aliás, as companhias de seguros na taxação dos seus clientes" (Professor Flaminio Fávero).

Nos casos de ficár bem demonstrada uma preexistência mórbida - ficará o empregado privado đa indenização? Não. A nova Lei Brasileira faculta, ào contrário da anterior, uma interpretação liberal. E nem poderia deixar de ser assim, preleciona o Professor FlamíNIO FÁyERo, dado o carater transacional da Lei de infortúnios. De fato, se a culpa do operário não o priva da indenização, porquê há de fazê-lo o estado anterior inteiramente extranho a sua vontade? pergunta o atual expoente máximo da Medicina Legal brasileira.

\section{III}

\section{O RERITO EM FACE DA SIMULAÇÃO DE PERTURBAÇÕES NEURO-PSÍQUICAS}

José Ingenieros, em séu célebre liv́ro "Simulação da loucura" que, consoante o Professor HenRIQue Roxo, é a obra mais perfeita a respeito do assunto, admite cinco grandes grupos de simuladores da alienação mental:

\footnotetext{
I - Simuladores de estados naníacos;

II - Simuladores de estados depressivos;

III - Simuladores de estados delirantes ou paranoicos;

IV - Simuladores de episódios psicopáticos em fundo neuropático;

V - Sinuladores de estados confuso-demenciais.
} 
1. Os simuladores de estados maníacos fazem-no desde: os simples estados dé excitação maníaca até os de mania com grande agitação. Fazem muito barulho, saltam e gritam, como se os demônios. os tangessem, mas, quando acreditam que não estejam a ser observados, buscam repousar e adormecer calmamente...

II - Os simuladores de estados depressivos fingeni-se atacados de profunda melancolia: silenciosos, quasi imoveis, parcos no comer- pensam que com essas atitudes conseguirão iludir o perito. .

III - Os simuladores de estados delirantes ou paranoicos procuram imitar o-delírio episódico dos degenerados e a paranóia. Ora fingem-se tomados de idéias de perseguíção, ora alegam a existência de alucinações na verdade invèntadas.

IV - Os simuládores de episódios psicopáticos em fundo neuropático simulam idéias delirantes, maxime as de perseguição e de grandeza.

$\mathrm{V}$ - Os simuladores de estados confusó-demenciais procuram fingir que se acham desmemoriados, confusos, obnubilados, etc.

Quando o perito suspeita encontrar-se perante um caso de perturbação mental simulada, o exame deve constar, segundo CHAvigNY, do seguinte:

I - Interrogatório e investigações sobre os antecedentes hereditários e pessoais;

II - Exame direto, o qual deverá ser subdividido em:

A) Exame psíquico;

B) Exame físico.

O exame psíquico abrangerá como partes principais :

a) A análise da fisionomia;

b) A análise dos atos;

c) O interrogatório;

d) A análise da palavra escrita.

O exame físico comportará um estudo:

a) Do estado geral do examinando (temperatura, pulso, etc);

b) Dos orgãos em particular;

c) Do estado da nutrição;

d) Dos estigmas de degeneração.

Quando nos defrontarmos com portadores de perturbações neuropsíquicas consequentes a traumatismos cranianos, devemos pensar na modelar lição do Professor Pacheco E Silva:

"LOUDET é de opinião que importa principalnente se estabelecer a relação do síndromo psíquico com o traumatismo e ter em conta, sobretudo, o tempo do aparecimento e o ritmo evolutivo do dito síndromo. O fator cronológico é um elemento fundamental na apreciação dos fatos e pode-se apresentar algumas vezes de forma iniprecisa e obscura. 
Assim, dever-se-á, ségundo aquele autor:

1. .) Comprovar-se a relação de causalidade (traumatismo-síndromo psíquico);

$\left.2 .^{\circ}\right)$ Avaliar a incapacidade e estabelecer a indenização ou as medidas legais correspondentes.

"Duas dificuldades podem então se deparar ao perito:

$\left.1 .^{\circ}\right)$ O exame tardio do traumatizado;

$\left.2 .^{\circ}\right)$ A ausência de dados técnicos sobre as condições materiais do acidente e sobre a sintomatologia imediata e mediata apresentada pelo traumatizado.

"Na apreciação do fator cronológico, que é de grande importância, compete ao perito averiguar:

$\left.1^{\circ}\right)$ Se a psicose ou as desordens mentais se seguiram imediatamente ao traumatismo;

$\left.2^{\circ}\right)$ ' Se a psicose surgiu mediatamente; tardios.

$3 .^{\circ}$ ) Se os transtornos mentais são distanciados ou muito

"Muitas vezes, o perito mais experimentado poderá deparar com sérios obstáculos para formular juizo seguro, em virtude do grande número de concausas em jogo e da"influência preponderante da personalidade prépsicótiça”

Não nos devemos esquecer que muito raro não é existir uma acentuada desproporção ou díscordância entre as perturbações nervosas acusadas pelo paciente e a natureza do traumatismo; em tais casos convem analisados "os antecedentes pessoais, a constituição individual, a emotividade, etc., porisso que poderão fazer vislumbrar, senão ver claramente, a verdadeira etiologia da doença e, portanto, solucionar as três incógnitas: - Foi o traumatismo a causa exclusiva do mal? - O traumatismo apenas patenteou uma predisposição já existente? - Criou o traumatismo uma predisposição que, em face dum dado fator, fez eclodir determinados distúrbios mentais?

Haveria ainda que tratar de muitas lesões corporais, perturbações funcionais e doenças que são comumente simuladas para fins especulativos. Naturalmerite a matéria não poderia ser aquí esgotada. Já muitos aspectos deste problema foram estudados em trabalhos anteriores nossos ("A SIMULAÇÃO EM INFORTUNÍSTICA", trabalho relatado na Segunda Semana Paulista de Medicina Legal, e "A SIMULAÇÃO EM INFORTUNÍSTICA E O NOVO CóDIGO PENAL", conferência pronunciada, em 14 de janeiro deste ano, na Sociedade de Medicina Legal e Criminologia de São Paulo). Pretendemos estudar outros aspectos de tão interessante assunto, a pouco e pouco, em trabalhos ulteriores.

Do exposto, porem, já se depreende quão delicada é, muitas vezes, a missão e a atuação do perito para chegar ao estabelecimento 
do nexo causal entre dada lesão corporal, perturbação funcional ou doença e dado traumatismo.

\section{IV}

\section{A SIMULAÇÃO EM INFORTUNISTICA EM FACE DO NOVO CóDIGO PENAL}

Para terminar, vamos resumir esquematicamente num quadro as diferentes modalidades de simulação e a sua correspondência, consoante nosso ponto de vista, com os incisos da nova Lei Penal que versam sobre a matéria. Antes, porem, ressaltemos que, para a existência duma perfeita correspondência entre o texto penal que entrará em vigor a $1 .^{\circ}$ de janeiro de 1942 e as diferentes modalidades de simulação analisadas no começo desta exposição, necessários se fazem os seguintes reparos:

1. ${ }^{\circ}$ ) Entendemos por SIMULAÇÃO VERDADEIRA — unicamente aquela em que há INVENÇÃO ou IMITAÇÃO duma lesão corporal, perturbação funcional ou doença. De conseguinte, sỏb essa denominação não incluimos, absolutamente, como o fez LÉon GALLEZ. na primeira modalidade da sua classificação ("Simulação propriąmente dita"), os casos em que o empregado atribue a un traumatismo uma lesão corporal, perturbação funcional ou doença preexistente, pois que, aquí, o que há, é propriamente uma IMPUTAÇÃO. INEXATA. Como já frisámos ao iniciar este trabalho, na SIMULAÇÃO VERDADEIRA há a SIMULAÇÃO DA CÁUSA e a SIMULAÇÃO DOS PRETENDIDOS EFEITOS do pseudo-acidente, isto é, há a INVENÇÃO DA CAUSA e a INVENÇÃO DOS PRETENDIDOS EFEITOS do pseudo infortúnio do trabalho.

Julgamos oportuno transcrever neste passo o que salientámos em o nosso trabalho "A Simulação em Infortunística":

"Devemos assinalar que a palavra simulação muita vez é empregada impropriamente. Assim, não é raro encontrar esta afirmação: "simular um ferimento é provocar o apareciniento dum 'quadro clínico que sugere a idéia duma lesão acidental".

“Tal não é verdade.

"Não se trata propriamente neste caso dum ferimento simulado, mas, sim, dum ferimento provocado voluntariamente. A fraude se assesta menos no ferimento do que na sua causa.

"Na simulação, consoante o acertado aviso de Ingenieros, as aparências exteriores duma cousa ou ação fazem confundîlla com outra, sem que efetivamente a equivalha.

"Quando se executa algo à semelhança doutra — que, destarte. serve de modelo - imita-se.

"Quando se não executa algo à semelhança doutra, porem se finge fazê-lo, - simula-se. 
"Convem meditada a lição de LÉon IMBERT:

"A verdadeira simulação seria a invenção duma doença propriamente dita: se, por exemplo, se faz acreditar na existência duma febre que realmente não existe, ou, ainda, numa falsa incontinência de urina, etc".

$2^{\circ}$ ) Dizemos que há DISSIMUULAÇÃO em infortunística quando dolosamente o empregado tenta ocultar ou efetivamente oculta uma lesão corporal, perturbação funcional ou doença.

Quándo a intenção fraudulenta se torna patente ao médico, antes que o embaidor tenha sido admitido à serviço - podemos falar propriamente em DISSIMULAÇÃO.

Quando, porem, já tenha o empregado atingido a primeira parte do seu objetivo (vale dizer - ver aprovado o contrato de locação de trabalho) e, após um lapso de tempo que julgar conveniente, procurar per en prática a segunda parte do seu plano (vale dizer atribuir uma origem traumática ao mal de que já sofria antes de ingressar no trabalho), não mais podemos falar com propriedade que há DISSIMULAÇÃO. Esta só teve a sua ocasião no momento em que o empregado tentou encobrir ou realmente encobriu a sua lesão corporal, perturbação funcional ou doença. Neste segundo momento da ação fraudulenta - não se trata mais de encobrir uma lesão corporal, perturbação funcional ou doença. Trata-se de atribuir a um traumatismo real ou fictício, uma lesão corporal, perturbação funciohal ou doença já preexistente. Nesta última eventualidade, o empregado não dissimula mas, sim, lança mão duma IMPUTAÇÃO INEXATA, servindo-se, naturalmente, daquele fingimento anterior. Aquí há uma IMPUUTAÇÃO FALSA (IMPUTAÇÃO INEXATA DOLOSA). A hipótese é regida, no novo estatuto penal, pelo corpo do art, 171.

A dissimulação, nos casos em apreço, quando diagnosticada, trará, é óbvio, para seu autor̀, o justo castigo: a não celebração do contrato de trabalho; para a companhia ou firma que procura a mão de obra trará um benefício: presservá-la-á dum futuro onus injusto, graças ao mèdico que procedęu ao exame clínico.

Por outro lado, aquele que, de acordo com o novo Código Penal (Art. $171, \S 2 .^{\circ}$, n $^{\mathrm{o}} \mathrm{V}$ ), "lesa o próprio corpo ou a saude com o intuito de haver indenização ou -valor de seguro", doutra cousa tambem nãa se serve senão - duma IMPUTAÇÃO FALSA, visto que atribure como resultante dum infortúnio do trabalho, uma lesão corporal, perturbação funcioñal ou doença que, absolutamente, não foi "produzida pelo exercício do trabalho ou em consequência dele" mas, em verdade, foi provocada voluntariamente (autolesão).

Para estas últimas hipóteses mui própria é a denominação de BOISSEAU — "ENFERMIDADES PROVOCADAS PROPRIAMENTE DITAS". São regidas, no novo Código Penal, como já se viu, pelo n..$^{\circ} \mathrm{V}$ do $\S 2 .^{\circ}$ do art. 171 . 


\section{A PERICIA MEdica NOS CASOS DE SIMULAÇÃo EM INFORTUNISTICA}

\section{Interprétação e esquema original de A. M. Leão Bruno}

\section{Novo Código Penal}

Art. 171 - Obter, para si ou para outrem, vantagem ilícita, em prejuizo alheio induzindo ou mantendo alguem em errormediante artifício, árdil, ou qualquer outro meio fraudulento:

$\S 2 .^{\circ}$. Nas mesmas penas incorre quem:

V. destrói, total ou parcialmènte, ou oculta coisa própria, ou lesa o próprio corpo ou a saude, oư agrava as consequências da lesão ou doença, com o intuito de haver indenização ou valor de seguro.

\section{Modalidade de simulação}

SIMULLAÇO VERDADEIRA. EXYGERAC̨ÃO CONCIENTE. IMPUTAC̨ÃO FALSA (oriunda duma DISSIMULAÇÃO).
IMPUTAÇÃO FALSA (oriunda duma AUTOLESÃO):

AGravaÇÃO VOLUNTARIA. 


\section{CONCLUSOES}

$1:{ }^{\mathrm{a}}$ - No que concerne às modalidades de simulação - é de suma importância a uniformização das diferentes classificações existentes.

2. ${ }^{a}$ - Sendo inúmeras as classificações que existem acerca dạs modalidades de simulação - fora de desejar, para que sejam evitadas errôneas interpretações, que se estabelecesse um critério seguro para presidir a tal uniformização, e, ainda, que se firmasse nitidamente o conceito de cada uma das modalidades de simulação.

$3 .^{a}$ - A classificação exposta no presente trabalho, com o conceito que o Autor empresta a cada uma das modalidades de simulação, preenche assim os requisitos científicos como os da Lei Penal Brasileira.

4. ${ }^{\mathrm{a}}$ - Do exposto deflue que fora de desejar a adoção de tal classificação.

II

5. - O estudo da simulação em infortunística revela quão es. pinhosa é, muitas vezes, a missão e a atuação do perito para chegar ao estabélecimento do nexo causal entre dada lesão corporal, perturbação funcional où doença e dado traumatismo.

$6 .^{\mathrm{a}}-$ Ressalta do exposto que é de se desejar, em infortunística, que a perícia médica seja efetuada unicamente por médicos legistas, idéia pela qual de há muito se vem batendo a Sociedade de Medicina Legal e Criminologia de São Paulo e que encontrou guarida na 2. Semana Paulista de Medicina Legal. 


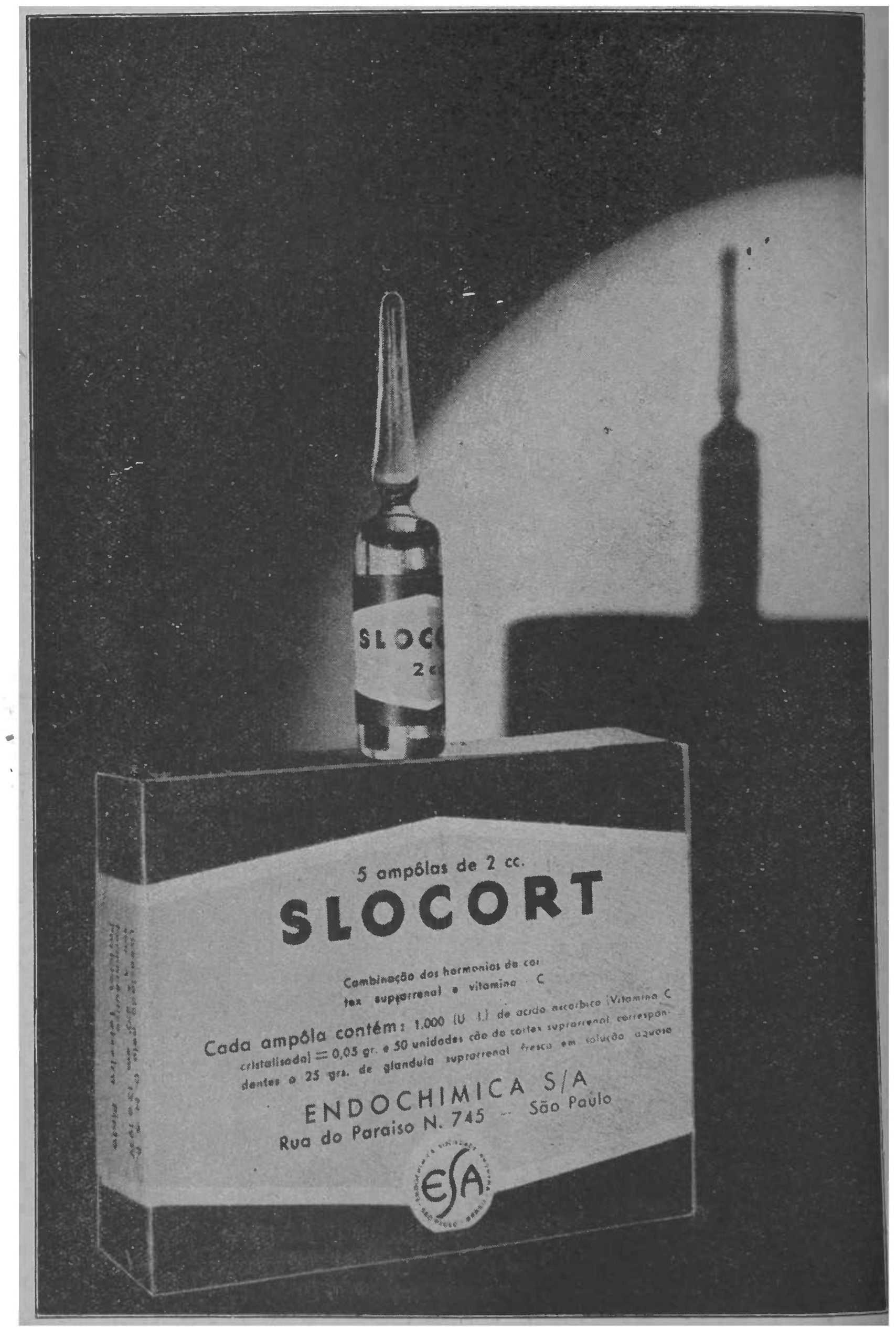

